\title{
BIBECHANA
}

ISSN 2091-0762 (Print), 2382-5340 (Online)

Journal homepage: http://nepjol.info/index.php/BIBECHANA

Publisher: Department of Physics, Mahendra Morang A.M. Campus, TU, Biratnagar, Nepal

\section{Schiff base metal complexes as a potential therapeutic drug in medical science: A critical review}

\author{
Narendra Kumar Chaudhary, Biswash Guragain, Siyanand Kumar Chaudhary, Parashuram \\ Mishra \\ Department of Chemistry, Mahendra Morang Adarsh Multiple Campus, Biratnagar, (Tribhuvan \\ University), Nepal \\ E-mail: chem_narendra@yahoo.com
}

\section{Article Information:}

Received: July 3, 2020

Accepted: August 2, 2020

Keywords:

Schiff base,

Metal complex

Superbugs

Chemotherapeutics

Antibiotic

\begin{abstract}
The discovery of new chemotherapeutics with novel bioactivities and functionalities to fight current emerging diseases has become the most significant research in pharmaceutical science. Schiff bases are versatile pharmacophores that can form complexes by chelation with metals of different oxidation states. Over a few decades of intensive research on metal-based drugs, Schiff base metal complexes have been considered as the active field of research in coordination chemistry, owing to their valuable applications in various fields of science. As therapeutic drugs, they have potential applications as antibiotic, antimicrobial, antitumor, antiviral, anti-inflammatory, analgesic, antifungal, and many more. There has been a global threat of drug resistance in medical science in recent years because most of the pathogenic organisms are developing the ability to deactivate drug substances. For this reason, it requires urgent attention from chemical and pharmaceutical scientists to address the severe challenges of multidrug resistance. This review summarizes the current developments in the last few decades' research on the chemotherapeutic activities of Schiff base metal complexes.
\end{abstract}

DOI: https://doi.org/10.3126/bibechana.v18i1.29841

This work is licensed under the Creative Commons CC BY-NC License. https://creativecommons.org/licenses/by-nc/4.0/

\section{Background}

The coordination chemistry of transition metal complexes has gained momentum in recent years because of their versatile applications in various fields of chemical and medical sciences and comprises a large body of bio-inorganic chemistry research [1]. It has inspired chemical researchers to design and fabricate novel metal complexes all over the world. Metal ions make the linkage between the drug substances and pathogenic organisms and thus the field of metal drug interaction chemistry is growing rapidly in the medical and chemical sciences [2]. Microbial interactions with a variety 
of metal ions at various oxidation states are sometimes beneficial or detrimental, depending on the physical and chemical nature of the metal ions [3]. The treatment of diseases by pure herbal medicines from nature's chest has been a quest of mankind since ancient times. Currently, there is a substantial decline in the use of pure herbal medicines because of the complexity of their chemical extraction and slow interaction with diseases [4]. Pharmaceutical research has expanded after the Second World War to include a massive screening of microorganisms for new antibiotics because of the discovery of penicillin. With the successful record of synthetic medicinal chemistry, the identification of new metabolites from living organisms would be the core pharmaceutical discovery efforts. The world is running out of antibiotics and the discovery of synthetic drugs is today's therapeutic desire for pharmaceutical research. However, many natural product-based drugs are in clinical practice that needs extensive research $[5,6]$.

Schiff base is the most familiar discovery of Hugo Schiff, who has called one of the founders of modern chemistry. The work of Professor Wohler excluded the concept of vis-vitalis theory, demonstrating that there is no metaphysical difference between organic and inorganic substances. The great pioneering work of Berzelius, Wohler, and Hugo Schiff changed the vision of thinking about organic chemical substances. Professor Schiff memorized himself by the word: Remember that you descend from Berzelius because Berzelius taught chemistry to the old Wohler and the old Wohler taught me. Professor Schiff, the native of Germany, has continued his research work in Italy and introduced himself as an Italian chemist $[7,8]$. After the novel work of Schiff in 1864, many researchers were involved in this research field and got success in the synthesis and structural design of this class of compounds.

The first metal-based drug that emerged in the late 19th century was cisplatin, whose serendipitous discovery as a potent anticancer drug unlocked the exploration of metal-based chemotherapeutic agents. It was the most effective anticancer drug in the market $[9,10]$. The resounding therapeutic success of cisplatin and its analogs has triggered tremendous effort in the search for alternative metal-based chemotherapeutic agents in the past few decades. Since then the metal-drug interactions in the field of coordination chemistry have been focused well and considered as an active field of research [11]. Therefore, there is an urgent to discover and characterize new drugs with enhanced activity, selectivity, bioavailability, and fewer side effects than conventional drugs to treat current diseases.

\section{Schiff base}

Schiff bases comprise one of the most widely used families of organic compounds, formed as the condensation product of the chemical reaction of the active carbonyl group and a primary amine. Their discovery and chemistry are the results of the great pioneer work of a German chemist, Hugo Schiff, in the year 1864. This has revolutionized chemical research in the field of coordination chemistry in the late $19^{\text {th }}$ century $[12,13]$. In researching aniline chemistry, he studied the reactions of aniline with many other aldehydes and finally reached the discovery of the imine-based organic compound Schiff base. They are also called anils, imines, or azomethines. This class of compounds is mainly recognized by the presence of an active imine $(-\mathrm{CH}=\mathrm{N}-)$ group that carries a potential binding site for the metal ions through nonbonding electrons of the nitrogen atom [14]. The structural unit of Schiff bases also possesses many other hetero-elements like oxygen and sulphur, as the main component elements for chelate formation with metals. The nature of donor atoms that act as coordination sites, their electronegativity, and steric factors largely determine the bonding ability of the ligands. By the presence of lone pair electrons on the $\mathrm{N}$-atom, the electron-donating character of the double bond, and 
the low electronegativity of nitrogen, the $\mathrm{N}$-atom of the azomethine group $(>\mathrm{C}=\mathrm{N})$ acts as a very good donor site and Schiff bases are considered as active ligands [15].

Recently, Schiff bases occupy a leading position in coordination chemistry and provide a significant attraction in creating chemical scaffolds due to their simplicity in preparation, variation in properties, biomedical, biochemical, and industrial applications [16]. There are several amines and carbonyl compounds in the library of organic chemistry that enables the synthesis of Schiff bases with diverse structural features. For the synthesis of Schiff bases, the basic carbonyl group may be aldehydes (aromatic or aliphatic) or a ketone. The stability of the imine group is controlled by the presence of substituent groups attached to the $(>\mathrm{C}=\mathrm{N})$ linkage. The general reaction for the formation of the Schiff base is illustrated in Scheme 1.

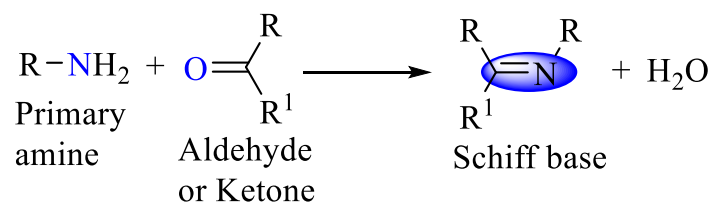

Scheme 1: Reaction scheme for Schiff base formation.

where $\mathrm{R}$ represents an alkyl, aryl, cycloalkyl, or heterocyclic group, which may be variably substituted and $\mathrm{R}^{1}$ may be an alkyl, aryl group, or $\mathrm{H}$ atom. The formation of the Schiff base is a reversible process and generally takes place by refluxing the mixture under neutral conditions or in the presence of acid or base catalysts. The formation is generally driven to completion by the separation of the product or removal of water.

\section{Metal complexes of Schiff base}

Many research papers have been published during the last few decades on the synthesis and pharmacology of Schiff base metal complexes. Schiff bases are versatile pharmacophores that cave in metal ions within their structural units because of the presence of various donor atoms [17,18]. Transition metal complexes of Schiff bases are generally formed by the chelation of Schiff base ligands with metal ions at variable oxidation states. The vacant d-orbitals of metal ions make available space for the easy coordination of nonbonding electrons of donor atoms of the ligand and even sometimes, this ligation takes place by deprotonation process. There is a general rule of coordination chemistry that chelation makes the complex compounds more stable due to electron circulation inside the ring and changes the physiological profile of the complexes $[19,20]$. Their stability increases when the chelate ring is five or six members. The aryl group bonded to the nitrogen or carbon of the azomethine group prevents them from rapid decomposition and polymerization.

A lone pair electron in the $\mathrm{sp}^{2}$ hybrid orbital of azomethine nitrogen is of considerable chemical and biological importance because it makes easy coordination with metals. Variation in the denticity of Schiff bases makes controls the stereochemistry of metal complexes, which affects their physiological profiles. These complexes carry a wide range of applications in the catalytic chemistry, analytical, clinical, and biochemical fields. In addition, they also possess considerable physiological activities [21-23]. The multifunctional activities of such metal complexes are the prime sources of metal-based research in chemical science. Many drug substances have metal ions that play a key role in the better success of biological activities [24]. Several studies have described the enhanced activities of metal complexes compared to free ligands. Recently, a large volume of research reports on Schiff bases highlighted them as a type of potential antibiotic, which by chelation with metals further enhances their potency. Chelation causes a drastic change in the biological properties of the ligands and metal moiety [25]. It has been reported that chelation is the cause and cure of many diseases, including 
cancer. The present study of the research focuses on the formation of several Schiff base ligands from different precursor compounds and their metal complexes with 3d-metal ions. These chelated complexes of Schiff bases are easily absorbed in human intestinal cells and increase their antibacterial strength.

\section{Chemotherapeutic applications}

Recent advances in coordination chemistry reveal Schiff base as a privileged ligand because most of the biomolecules in the living system are structurally similar to this class of compounds. The biofunctional activity of metal-based complexes in medicine and chemotherapy has spurred the growth of interest in the scientific world in the past few decades, after the successful clinical application of cisplatin as a potential anticancer drug. Therefore, metal-drug interaction in medical science is becoming a subject of great research interest [2628]. The transition metal chemistry of Schiff bases gained momentum in the late $19^{\text {th }}$ century and since then, metal-based drugs of Schiff bases drew the significant interest of researchers in medical science for their immense biological activities. Most of the metals are unnatural to the human body because they have no effective mechanism for their rejection and toxic behavior [29], and there has been a rapid expansion in the research and development of novel metal-based drugs with improved pharmacological properties. Several medical problems that arise due to free metal ion toxicity may be ameliorated by their chelation with ligands.

Schiff base metal complexes have important biological applications as antibacterial, antifungal, antitumor, analgesic, anti-inflammatory, and antimicrobial agents. It has been found that some drugs have greater activity when administered as metal complexes than free organic compounds [30,31]. The discussion in this review is limited to the chemotherapeutic applications of Schiff base ligands and their metal complexes. The potential biological activity of Schiff base metal complexes is related to the presence of lone pair electrons that participate in the anchoring of biomolecules in the living body.

Most of the penicillin drugs as antibacterial agents have reported resistance against some pathogenic bacterial strains due to the formation of $\beta$ lactamases enzymes, but their metal complexes show enhanced activity with them. Penicillin-based Schiff base ligands are versatile pharmacophores that give an easy binding template for several metal ions. The Schiff base ligands (1 and 2) obtained by the condensation of amoxicillin trihydrate with pyridine-2-carbaldehyde and pyridine-3carbaldehyde are rich donor atom-containing compounds, which can easily form metal complexes through interactions with various transition metals. The Schiff base ligands and their metal complexes were characterized by various spectral and physicochemical techniques and the antibacterial assay screening was assessed by the Kirby-Bauer paper disc diffusion technique. Co(II), $\mathrm{Ni}(\mathrm{II}), \mathrm{Cu}(\mathrm{II})$, and $\mathrm{Zn}$ (II) complexes of such ligands have shown better antibacterial activity against several bacterial pathogens such as E. coli, $P$. vulgaris, K. pneumoniae, and $S$. aureus[32,33]. Bidentate NS ligands (3), obtained by the condensation of S-2-methylbenzyldithiocarbazate (S2MBDTC) with 2-methoxybenzaldehyde (2MB) and 3-methoxybenzaldehyde (3MB) form metal complexes with acetate salts of $\mathrm{Cu}$ (II), $\mathrm{Ni}$ (II) and $\mathrm{Zn}$ (II) metals in a 1:2 metal:ligand ratio. They were evaluated for their biological activities against estrogen receptor-positive (MCF-7) and estrogen receptor-negative (MDA-MB-231) breast cancer cell lines using the MTT assay method. The $\mathrm{Cu}$ (II) complex showed remarkable cytotoxic activity against cancer cell lines. The DNA binding study of the $\mathrm{Cu}$ (II) complex with calf thymus DNA by spectrophotometric technique also revealed a good binding affinity [34]. Schiff bases derived from 3,3'-diaminodipropylamine and different benzaldehyde derivatives were observed to have bacteriostatic activity against several pathogenic 
gram-positive and gram-negative bacteria. They also responded to very good antifungal activities. Matar et al. (2015) evaluated the in vitro antimicrobial activity of Schiff base ligands against various strains of human pathogenic bacteria and a fungal strain, Candida albicans, by a two-fold serial dilution method. The antibacterial study was done by the disc diffusion method using test samples at a concentration of $250 \mu \mathrm{g} /$ disc. The compounds responded better inhibitory activity against gram-positive bacteria than against gramnegative and fungal strains. The antibacterial potency of the ligand (4) increased with the $\mathrm{NO}_{2}$ moiety compared to $\mathrm{H}$ and $\mathrm{OH}$ in other derivatives. Moreover, the Schiff base (5) exhibited significant anti candida activity at a concentration of $24 \mu \mathrm{g} / \mathrm{ml}$ [35].

Melonal is considered an interesting aldehyde used in sensory science with excellent sensory properties. Chemically, it is 2,6-dimethyl-5heptanaldehyde. In one of the previous studies, $\mathrm{Cu}(\mathrm{II}), \mathrm{Ni}(\mathrm{II}), \mathrm{Co}$ (II), and $\mathrm{Cr}$ (III) complexes of Schiff base ligand (6) obtained from 4fluoroaniline and 2,6-dimethylhept-5-enal were tested in vitro to examine their antibacterial and antifungal potency. An in vitro antimicrobial study was conducted against three gram-negative (E. coli, $S$. typhi, $P$. aeruginosa), three gram-positive ( $S$. aureus, B. subtilis, B. megaterium) bacterial strains and six fungal strains $(C$. albicans, $P$. chrysogenum, A. niger, A. flavus, A. fumigatus, and C. oxysproum) at six different concentrations. The results of antifungal studies are more pronounced, but the antibacterial results are moderate. Among them, the $\mathrm{Ni}$ (II) complex exhibited better antibacterial activity than the others. The study also revealed better antifungal activity of the $\mathrm{Co}$ (II) complex against Penicilliumchrysogenum[36].

Schiff base complexes containing a thiazole moiety bear special interest for anticancer activity. In a previous study, a Schiff base ligand (7) was prepared by the condensation of salicylaldehyde and 2-amino-4-phenyl-5-methyl thiazole and it was complexed with $\mathrm{Co}(\mathrm{II}), \mathrm{Ni}(\mathrm{II}), \mathrm{Cu}(\mathrm{II})$, and $\mathrm{Zn}$ (II) salts. The synthesized compounds have interacted for anticancer activity study against different human tumor cell lines: MCF-7, HepG2, lung carcinoma A549, and colorectal cancer HCT116. For the cytotoxicity assay, test compounds were dissolved in DMSO at a concentration of $1 \mathrm{gm} / \mathrm{mL}$ and further concentration of the solutions was prepared by serial dilution technique. The cytotoxicity of the tested compounds was expressed by $\mathrm{IC}_{50}$ values, which showed a $50 \%$ cytotoxic effect against cancer cell lines after $48 \mathrm{~h}$ of exposure to the tested compounds. The order of $\mathrm{IC}_{50}$ values with respect to HepG2 and $\mathrm{MCF}-7$ cancer cell lines of the compounds was $\mathrm{Zn}$ (II) complex, $\mathrm{Ni}$ (II) complex, $\mathrm{Cu}(\mathrm{II})$ complex, $\mathrm{Co}(\mathrm{II})$ complex and ligand (7). For A549 cancer cell lines, the $\mathrm{Zn}$ (II) complex and $\mathrm{Ni}$ (II) complex showed anticancer activity at $\mathrm{IC}_{50}$ values of 5.30 and 9.10 $\mu \mathrm{g} / \mathrm{mL}$, respectively. The study also revealed potent inhibition of the $\mathrm{Zn}(\mathrm{II})$ complex (8) against human TRK in all four tested cell lines [37].

Electron-donating and electron-withdrawing groups present in Schiff base have a profound effect in demonstrating biological functions. The hydrazide Schiff bases of vanadium acetylacetonate complexes could be exemplified to show this type of behavior. Such Schiff bases (9 and 10) were prepared by the condensation of 4-(diethylamino)2-hydroxybenzaldehyde with 4-nitrobenzohydrazide and 4-methoxybenzohydrazide. Schiff bases (11 and 12) were prepared by refluxation of 4(dimethylamino)benzaldehyde with 4-nitrobenzohydrazide and 4-methoxybenzohydrazide. Their vanadium complexes were synthesized by treatment with vanadium acetylacetonate. Their antibacterial profile exhibited the best activity against several strains of S. aureus and E. faecalis bacteria [38].

Chitosan-based polymeric Schiff base ligands and their metal complexes are highly toxic to human breast cancer cell lines. Barbosa et al. (2017) prepared biopolymeric Schiff bases from chitosan and salicylaldehyde derivatives and also successfully synthesized their $\mathrm{Pd}(\mathrm{II})$ and $\mathrm{Pt}(\mathrm{II})$ complexes. Their structures were optimized on the 
basis of various spectroscopic techniques such as FT-IR, UV-Vis, ${ }^{1} \mathrm{H}-\mathrm{NMR},{ }^{13} \mathrm{C}-\mathrm{NMR}$, and mass spectrometry. Cytotoxic interaction of ligands and their metal complexes against the human breast cancer cell line (MCF-7) was done by MTT assay technique and found enhanced toxicity compared to non-modified chitosan. They reached in the conclusion that the cytotoxicity of complexes is a concentration-dependent variable. Moreover, the in vitro antibacterial and antifungal tests of the compounds against Pseudomonas syringae and Fusariumgraminearum showed good results [39]. Heterocyclic base-based Schiff base ligands and their metal complexes also possess significant antibacterial, antifungal and anticancer activities. In a previous study, Abd El-Halim et al. (2017) prepared this type of Schiff base (13) from quinoline-2-carboxaldehyde and 2-aminophenol and also synthesized various metal complexes with 1.10-phenanthroline. The antibacterial and antifungal activities were evaluated separately in vitro for all types of ligands and the metal complexes by the agar well diffusion method and the anticancer activity was estimated by the viability assay technique. Cytotoxicity evaluation was carried out on two different cancerous cells (breast cancer cell line MCF-7, and colon cancer cell line HCT-116). In this study, the Schiff base ligand was found more potent than metal complexes [40]. However, the $\mathrm{Cu}$ (II) complex showed the highest $\mathrm{IC}_{50}$ against the breast cancer cell line (MCF-7).

The remarkable antitumor activity of lanthanum and cerium complexes of (E)-N'-[1-(2pyridinyl)ethylidene]isonicotinohydrazoneSchiff

base ligand was noticed when they were tested in vitro using the MTT assay technique against the human lung cancer cell line A549, and human gastric cancer cell lines BGC823 and SGC7901. The $\mathrm{IC}_{50}$ value of free ligand was reported to be $41.8 \mu \mathrm{mol} / \mathrm{L}, 39.2 \mu \mathrm{mol} / \mathrm{L}$ and $43.5 \mu \mathrm{mol} / \mathrm{L}$ and La-complex $\quad 11.5 \mu \mathrm{moi} / \mathrm{L}, \quad 13.3 \mu \mathrm{mol} / \mathrm{L} \quad$ and 15.6 $\mu \mathrm{mol} / \mathrm{L}$ against A549, BGC823, and SGC7901 cancer cell lines respectively. On the contrary, the
Ce-complex was found prone to inhibit the growth of cancerous cells at the concentration of 10.9 $\mu \mathrm{mol} / \mathrm{L}, 12.6 \mu \mathrm{mol} / \mathrm{L}$, and $14.8 \mu \mathrm{mol} / \mathrm{L}$ for $\mathrm{A} 549$, BGC823, and SGC7901 cancer cell lines respectively. Based on the $\mathrm{IC}_{50}$ value of all three types of compounds, metal-based complex compounds have seemed hopefully more effective in terms of inhibiting proliferation and inducing apoptosis in tumor cell lines [41]. The mixed ligand cobalt complex of Schiff bases (E)-2,4-dichloro-6(((2-hydroxy-5-nitrophenyl)imino)methyl)phenol

(14) and (E)-2,4-dibromo-6-(((2-hydroxy-5nitrophenyl)imino) methyl)phenol (15) with pyridine showed significant growth inhibition activity in three human skin cancer cell lines (A431, HT-144 and SK-MEL-30) [42]. The in vitro assessment of antitumor activity of (14 and 15) and their Co-complexes demonstrated that the $\mathrm{IC}_{50}$ values of the Co-complexes were significantly less than the free ligand. Based on the comparative study, the $\mathrm{IC}_{50}$ values of Co-complex of (14) were reported to be11.3 $\pm 2.7 \mu \mathrm{M}, 17.8 \pm 3.1 \mu \mathrm{M}$, and $19.8 \pm 4.8 \mu \mathrm{M}$ against A-431, HT-144, and SKMEL-30 respectively.

Kashyap, et al. (2018) explored the antimicrobial and cytotoxic activity of newly synthesized metal complexes derived from the Schiff base of mhydroxybenzaldehyde and 4-amino antipyrine. The structure and binding of metals with the Schiff base ligand were confirmed by UV-Vis, FT-IR, NMR, and TGA spectrum analysis. The screening of metal complexes followed by the Sulforhodamine$\mathrm{B}$ assay against the selective human colorectal carcinoma (HCT116) cancer cell lines were found very informative for the determination of their action and usefulness in the field of biomedical science. HCT 116 cells were seeded at 2500 cells/well (96 well plates) and allowed to attach overnight. Trichloroacetic acid was used as the cell fixing reagent and $0.4 \%(\mathrm{w} / \mathrm{v})$ sulforhodamine B in $1 \%$ acetic acid as the dye reagent to find the total viable count cells in terms of $\mathrm{IC}_{50}$-values at $570 \mathrm{~nm}$ of wavelength. The maximum permitted concentration of the complex used for their 
cytotoxicity measurement was $100 \mu \mathrm{g} / \mathrm{ml}$. The metal complexes of Schiff base were found very prone to kill the fungi and less prone to inhibit the growth of bacteria when they were screened against the selective pathogenic gram-positive bacteria such as Staphylococcus aureus (MTCC3160), and the gram-negative bacteria Klebsiellapneumoniae, Salmonella typhi, Escherichia coli (MTCC 443) and the fungal species; Aspergillusniger (MTCC 281), and Candida albicans (MTCC 227). The serial dilution method was adopted to evaluate their antimicrobial affinity. The bacteria were grown in double-strength nutrient broth and fungi in Sabouraud dextrose broth. Similarly, the cytotoxicity of the synthesized compounds was found below the efficiency of standard 5fluorouracil drugs [43]. Shaygan et al. (2018) have made a new approach for the determination of the antibacterial activity of newly synthesized Co(II) metal complexes derived from the Schiff base (16 and 17) of terephthalaldehyde and ortho-aniline. They showed a remarkable bactericidal potency of the complex against bacterial pathogens such as $E$. coli(ATCC:25922),

Serratiamarcescens (ATCC:13880), P. aeruginosa (ATCC:27853) (gram-negative bacteria), B. subtilis (ATCC:6633), and $S$. aureus (ATCC:6838) (gram-positive bacteria) [44]. The most common method of antimicrobial activity assessment like disc diffusion and broth dilution methods were found to be admitted in their work. In the disc diffusion method, first, the paper disc was impregnated in the stock solution $(100 \mu \mathrm{L})$ of the metal complex and then inoculated into the bacterial culture plate. The plate was incubated for $18-24 \mathrm{~h}$ at $35^{\circ} \mathrm{C}$ and their antibacterial properties were recorded by measuring the diameter of the zone of inhibition in mm units. In contrast to the disc diffusion method, the broth dilution method was accomplished by the incubation of bacteria suspended in agar media in the presence of metal complex (2 to $0.00195 \mathrm{gm} / \mathrm{mL}$ ) at $35^{\circ} \mathrm{C}$ for $18-24 \mathrm{~h}$. The complex was found more effective against Pseudomonas aeruginosa with a diameter inhibition zone of
$17 \mathrm{~mm}$ and a minimum inhibitory concentration value of $0.15 \mathrm{mg} / \mathrm{mL}$.

A new series of mononuclear Fe(II), Co(II), Ni(II), $\mathrm{Cu}$ (II) and $\mathrm{Pd}(\mathrm{II})$ metal complexes, resulting from the metalation of tetradentatemacrocyclic nitrogen ligands, were screened in vitro against two different varieties of cancer cells; one human breast cancer cells (MCF-7) and another human hepatocarcinoma cells (Hep-G2). At first, the cells were plated in 96multiwell plate (104 cells/ plate) for $24 \mathrm{~h}$ for their attachment on the plate and to recover the monolayer of cells, and then treated with various concentrations $(0,2.5,5,10,20 \mu \mathrm{g} / \mathrm{mL})$ of metal complex solution. Monolayer cancerous cells inoculated with metal complexes were incubated for $48 \mathrm{~h}$ at $38{ }^{\circ} \mathrm{C}$ in $5 \% \mathrm{CO}_{2}$. In the incubated state, the cells were stained with Sulfo-Rhodamine-B stain and the excess staining reagent was removed by washing several times with acetic acid. The color intensity of the samples was measured using ELISA reader and the cytotoxic activity of all the metal complexes was expressed as $\mathrm{IC}_{50}$ values. Surprisingly, the metal complexes were found more active in destroying the toxic cells [45]. The $\mathrm{IC}_{50}$ values of the $\mathrm{Ni}$ (II) complex for respective $\mathrm{MCF}-7$ and Hep-G2 were reported to be $1.6 \mu \mathrm{g} / \mathrm{mL}$ and 1.7 $\mu \mathrm{g} / \mathrm{mL}$. The destruction of cancerous cells in the rapid mode is believed due to the interaction of the Schiff base with transition metals.

$\mathrm{Cu}$ (II) metal complexes derived from the Schiff base of quinoline-8-carbaldehyde and 4-aminobenzoic acid methyl ester or 4-amino-benzoic acid ethyl ester have gained importance in biomedical science. They are known as anticancer agents. The measurement of their action as toxic cell growthinhibiting agents has promoted the use of metal complexes as an excellent cytotoxic drug in the chemotherapeutic field. The cytotoxicity study of the metal complex was assessed by the MTT standard method in which the cells were seeded $\left(5 \times 10^{3}\right.$ cells/well $)$ in a 96 -well plate, and cultured for $24 \mathrm{~h}$ in $5 \% \quad \mathrm{CO}_{2}$ and then the metal complexes $(0-100 \mu \mathrm{M})$ were added and further incubated for $48 \mathrm{~h}$. Subsequently, $10 \mu \mathrm{L}$ of MTT 
solution $(5 \mathrm{mg} / \mathrm{mL})$ was added into the previously incubated cells and then cultured for $5 \mathrm{~h}$. The ELISA microplate was used to measure and calculate the $\mathrm{IC}_{50}$ values of the compound. Moreover, the complexes have shown excellent interaction for binding to DNA by intercalating mode and fit well into the curved contour of the DNA target at the minor groove region [46].

Andiappan, et al. (2018) have investigated the anticancer property of a metal complex (19) derived from the Schiff base (18) of 2,3diaminopyridine and anthracene-9-carbaldehyde ligands.

They characterized compounds by physicochemical analysis (molar conductivity, $\mathrm{pH}$ measurement, elemental analysis) and spectroscopic techniques (FT-IR, UV-Vis, mass-spectra, ${ }^{1} \mathrm{H}-\mathrm{NMR},{ }^{13} \mathrm{C}$ NMR). They have reported the excellent anticancer activity of the metal complexes based on their performance against the selective VERO, human breast cancer cell (MCF7), and cervical (HeLa) cancer cell lines [47]. The brutality of metal complexes against the selective cancerous cells was disclosed when they were treated with various concentrated solutions $(5,10,25,50,75$, and 100 $\mu \mathrm{g} / \mathrm{ml}$ ) of the metal complexes to find their $\mathrm{IC}_{50}$ values after their $24 \mathrm{~h}$ incubation. They showed that the complex with Er and Pr metals was more potent to inhibit the survival of Vero, MCF7, and HeLa cells and varied when the concentration of the metal complex was changed.

Chioma et al. (2018) reported the antimicrobial and antioxidant properties of heteroleptic divalent metal complexes of pyrimidinyl Schiff base ligand (20)with 2,2'-bipyridine and a series of divalent $\mathrm{Mn}, \mathrm{Co}, \mathrm{Ni}$, and $\mathrm{Zn}$ metal ions. They synthesized the Schiff base ligand (HL) by the condensation of 2-amino-4,6-dimethylpyridine with 2-hydroxy-1naphthaldehyde in the presence of acetic acid as a catalyst. The complexes were characterized by elemental analysis, conductivity, and $\mathrm{pH}$ measurements. They were further characterized by UV-Vis, FT-IR, ${ }^{1} \mathrm{H} /{ }^{13} \mathrm{C}-\mathrm{NMR}$, and mass spectrometry techniques. The compounds were used against the clinical isolates of gram-positive and gram-negative bacteria for the measurement of their antibacterial activity and also treated against some selective fungal species. The results of their in vitro screening against pathogenic microorganisms proved that the compounds were effluent for antimicrobial properties. In addition, the action of Schiff base ligand metal complexes as the antioxidant agent was evaluated by ferrous ion chelating assay and DPPH radical scavenging assay, in which the metal complexes showed their excellent performance compared to ascorbic acid [48].

Kuate et al. (2018) have reported the selective antimicrobial activity of metal complexes of Schiff base ligand (21) derived from the condensation of 4-Dimethylaminobenzaldehyde with glycylglycine. They were tested for antimicrobial evaluation against four bacterial and two fungal specimens via the disc diffusion technique. Based on the comparative result, they reached in the conclusion that the $\mathrm{Zn}$ and Ni inclusive Schiff base complexes were more efficient against $C$. neoformans, $S$. aureus, and $S$. thyphi pathogens than the other metal complexes with MIC values of $2 \times 10^{-3}$, $2.5 \times 10^{-2}$, and $2 \times 10^{-2}$ respectively [49]. In the fight against multidrug-resistant pathogens, it is advised often used narrow-spectrum antibiotics [50], i.e. the drugs showing very good activity against very selective pathogens like those in the present work are preferred.

Abu-Khadra et al. (2018) prepared a Schiff base ligand (22) from sulfacetamide (N-[4-(aminophenyl)sulfonil]acetamide) and 2thiophenecaroboxaldehyde and also synthesized a series of $\mathrm{Ag}, \mathrm{Cr}, \mathrm{Co}, \mathrm{Ni}, \mathrm{Cu}$, and $\mathrm{Zn}$ metal complexes. They tried out to establish their antimicrobial activity against pathogenic grampositive, gram-negative, and some fungal species by deploying the agar diffusion technique [51]. All the complexes were found potent to inhibiting the growth of microorganisms. They reported such astonishing results with cobalt complexes 
surpassing the activity of the standard antifungal agent Amphotericin $\mathrm{B}$, and that the $\mathrm{Cr}$ and $\mathrm{Cu}$ complexes were overall efficacious with activity close to the standard antimicrobials. Hence, they concluded that the metal complex of (21) is prone to act as an antimicrobial agent.

Heteroleptic metal complexes of pyrimidinyl-based Schiff base ligand also possess good antimicrobial activity against various pathogenic bacteria and fungi. In a previous study, Festus et al. (2019) synthesized $\mathrm{Mn}(\mathrm{II}), \mathrm{Co}(\mathrm{II}), \mathrm{Ni}(\mathrm{II})$, and $\mathrm{Cu}(\mathrm{II})$ complexes of novel Schiff base ligand (23) (2-(4,6dimethylpyrimidin-2-ylamino)naphthalene-1,4dione and 2,2'-bipyridine) and appraised them antimicrobial evaluation against $S$. aureus, E. coli, $P$. aeruginosa, $B$. cereus, $P$. mirabilis, $K$. oxytoca, $A$. niger, A. flevus, and $R$. stolonifer organisms following the agar-well diffusion method. For this study, they seeded $0.2 \mathrm{~mL}$ of $24 \mathrm{~h}$ grown microbial culture in each plate and bore wells with the sterile cork of $7 \mathrm{~mm}$ diameter and introduced the tested samples prepared at $10 \mathrm{mg} / \mathrm{mL}$ concentration in DMSO. The study revealed moderate to some very good antimicrobial activity, even surpassing the control drug's activity several times [52]. The antioxidant capacity of all the synthesized complexes was good and the ligand showed even better activity than the standard ascorbic acid.

A novel bidentate Schiff base ligand (24)(E)-1-(4((E)-(4-(diethylamino)-2-hydroxybenzyli-

dene)amino) phenyl)ethanoneoxime was synthesized by the condensation of 1-(4aminophenyl) ethanoneoxime and 4Diethylaminosalicylaldehyde and metallated with $\mathrm{Co}(\mathrm{II}), \mathrm{Ni}(\mathrm{II})$, and $\mathrm{Cu}(\mathrm{II})$ for the formation of complexes. They are oxime functional groupcontaining metal complexes. They were screened in vitro antimicrobial study against two gram-positive bacteria (S. epidermidis and S. aureus), four gramnegative bacteria (E. coli, $P$. aeruginosa,
Salmonella, and Klebsiella spp.) and a fungal species Candida albicans. The results showed promising antimicrobial activity with almost all compounds against Salmonella spp. and Candida albicans, moderate activity against $S$. epidermidis and Klebsiella spp., but nil activity against $S$. aureus, E. coli, and P. aeruginosa[53]. A good lead to narrow-spectrum antibiotics could be expected from such compounds.

Cisplatin, a Pt-complex, is the first metal-based inorganic complex used in the treatment of human cancer that has opened the door of the unexplored world of metal-based drugs. The other Schiff base platinum complexes also possess a similar type of antitumor activity. Al-Aghbari et al. (2019) synthesized a $\mathrm{Pt}(\mathrm{II})$ complex (26) of Schiff base (25) by refluxing the ligand with $\mathrm{K}_{2} \mathrm{PtCl}_{4}$ in methanol for $24 \mathrm{~h}$. The Schiff base ligand was synthesized by refluxing a mixture of 2-(4isobutylphenyl)propanehydrazide and 2,3,4trihydroxybenzaldehyde in methanol and studied for anticancer activities. The complex showed higher cytotoxic activity than the ligand on both HeLa cells and PC3 cells, although both compounds were less potent than the model drug, cisplatin [54].

Owing to adverse effects on human health, several metal-based drugs with antitumor activities have limited clinical applications and thus, require extensive research for the development of efficient and less toxic anti-tumor drugs. In search of such therapeutic drugs, Deng et al. (2019) synthesized five $\mathrm{Pt}(\mathrm{II})$ complexes with a modified aroylhydrazone Schiff base ligand (27) and studied in vitro anti-tumor activity. They observed remarkable cytotoxicity of the compounds after complexation with Pt. The $\mathrm{IC}_{50}$ values of compound (28) against A549 and A549cisR cells were even lower than that of cisplatin[55]. 
<smiles></smiles>

(1)<smiles>CC(C)(C)C1SC2C(NC(=O)C(N=[W])c3ccc(O)cc3)C(=O)N2C1C(=O)O</smiles>

CH

(2)<smiles>COc1ccccc1/C=N\NC(=S)SCc1ccccc1C</smiles>

(3)

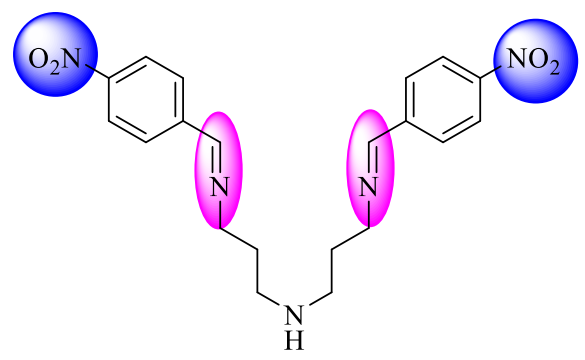

(4)

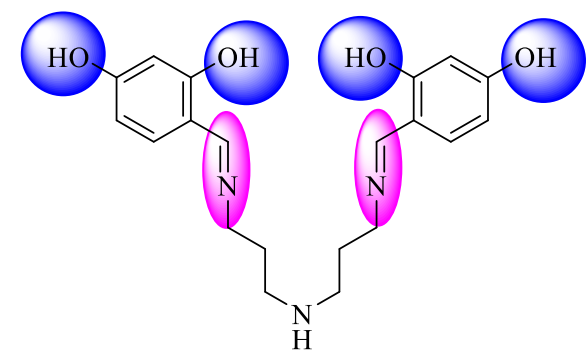

(5)

bis(3-((4-nitrobenzylidene)amino)propyl)amine

4,4'-(((azanediylbis(propane-3,1-diyl))bis(azaneylylidene)) bis(methaneylylidene))bis(benzene-1,3-diol)<smiles>CC(C)=CCCC(C)C#Cc1ccc(F)cc1</smiles>

(6)

(Z)-N-(4-fluorophenyl)-2,6-dimethyl hept-5-en-1-imine<smiles>Cc1sc(N=CC2CCCCC2)nc1-c1ccccc1</smiles>

$\mathrm{HO}$

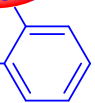

(E)-2-(((5-methyl-4-phenylthiazol-2-yl) imino)methyl)phenol Schiff base

(7)

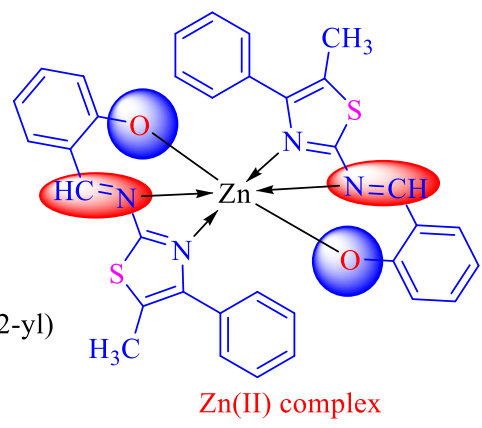

(8)<smiles>CCN(CC)c1ccc(/C=N/NC(=O)c2ccc([N+](=O)[O-])cc2)c(O)c1</smiles>

(9)<smiles>COc1ccc(C(=O)N/N=C/c2ccc(N(C)C)cc2)cc1</smiles>

(12)
(10)

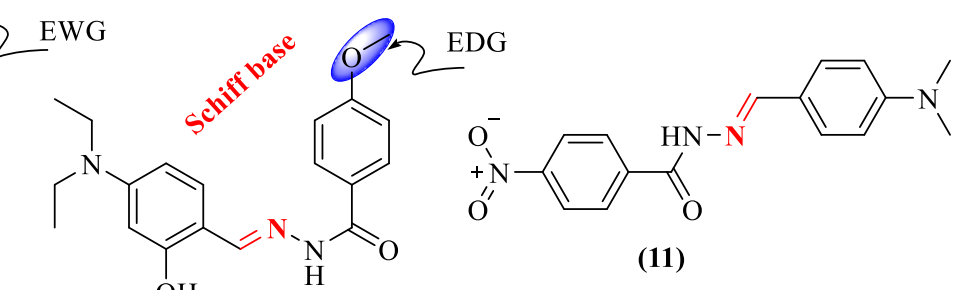

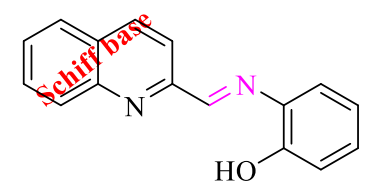

(E)-2-((quinolin-2-ylmethylene)amino)phenol

(13) 
<smiles>O=[N+]([O-])c1ccc(O)c(/N=C/c2cc(Cl)cc(Cl)c2O)c1</smiles>

(E)-2,4-dichloro-6-(((2-hydroxy-5nitrophenyl)imino)methyl)phenol

(14)

(17)<smiles>Cc1cc(C)nc(N=Cc2cc3ccccc3cc2O)n1</smiles>

3-\{(E)-[(4,6-dimethylpyrimidin-2-yl)iminol\}naphthalen-2-ol

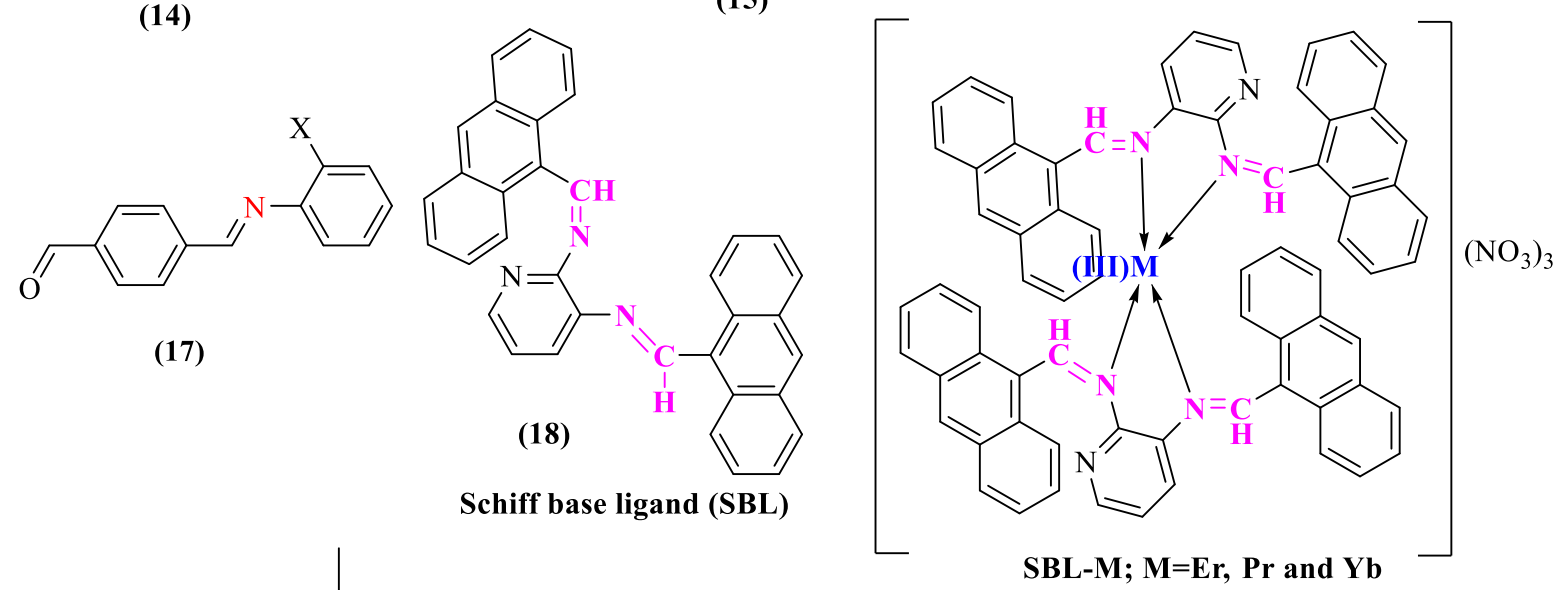<smiles>O=[N+]([O-])c1ccc(O)c(/N=C/c2cc(Br)cc(Br)c2O)c1</smiles>

(E)-2,4-dibromo-6-(((2-hydroxy-5 -nitrophenyl)imino)methyl)phenol

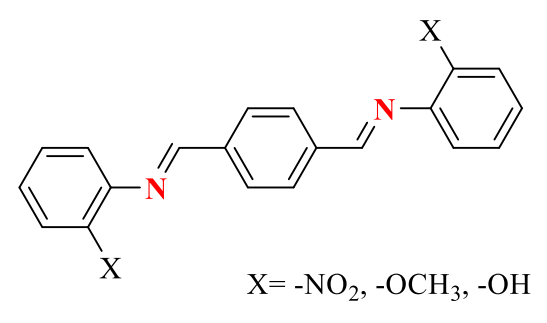

(16)

SBL-M; M=Er, Pr and Yb

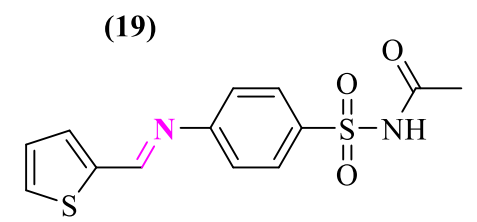

(E)-N-(4-(thiophen-2-ylmethyleneamino) (E)-2-(4-dimethylbenzydiamino) glyclyglycine phenylsulfonyl)acetatmide

(21)

(22)<smiles>Cc1cc(C)nc(NC2=CC(=O)c3ccccc3C2=O)n1</smiles>

2-((4,6-dimethylpyrimidin-2-yl)amino) naphthalene-1,4-dione

(23)<smiles>CC(C)Cc1ccc(C(C)C(=O)NN=Cc2ccc(O)c(O)c2O)cc1</smiles>

Schiff base ligand $\mathbf{L}$

(25)

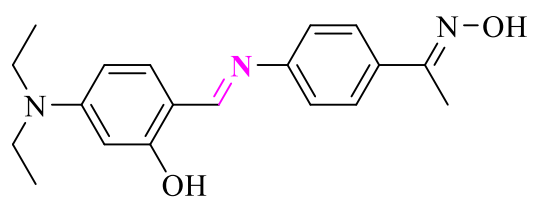

(E)-1-(4-(((E)-4-(diethylamino)-2-hydroxybenzylidene)amino) phenyl)ethan-1-one oxime

(24)

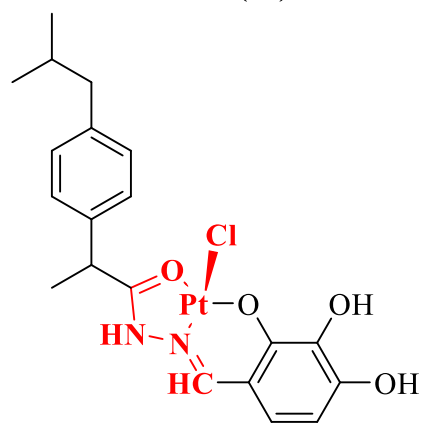

(26)<smiles>[R]c1ccc(O)c(C#CNC(=O)c2ccccc2)c1</smiles>

Hydrazone Schiff base 
<smiles></smiles><smiles>COc1cccc(/C=N/c2nc3ccccc3[nH]2)c1O</smiles>

(E)-2-(((1H-benzo[ $d]$ imidazol-2-yl) imino)methyl)-6-methoxyphenol

(29)

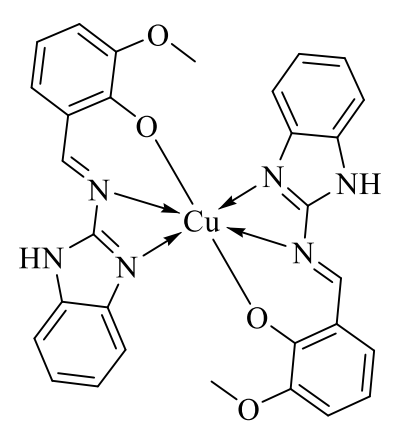

Complex-1

(30)

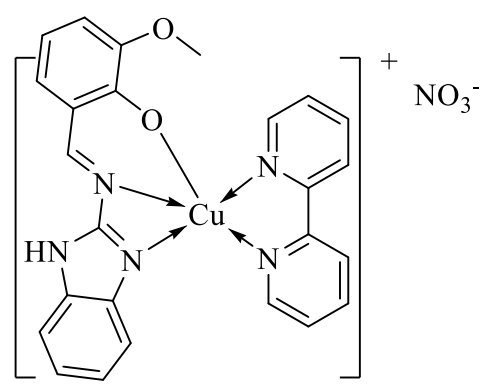

Complex-2

(31)

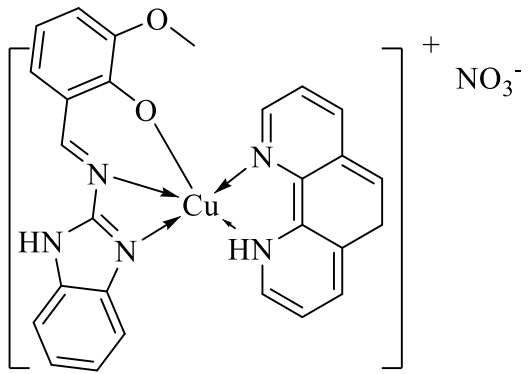

Complex-3

(32)

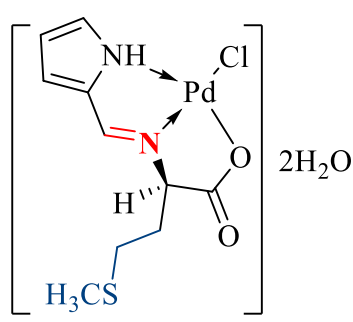

Complex 1

(36)<smiles>[R]C(=O)[C@H](N=Cc1ccc[nH]1)C([R])[R]</smiles>

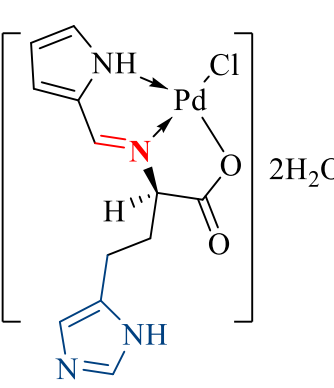

Complex 2

(37)

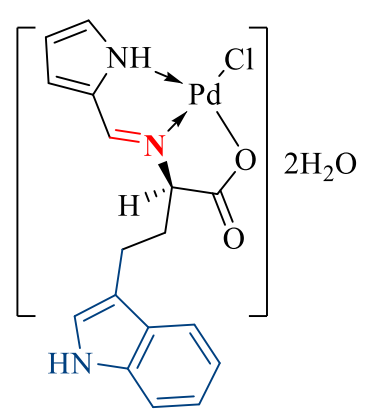

Complex 3

(38)

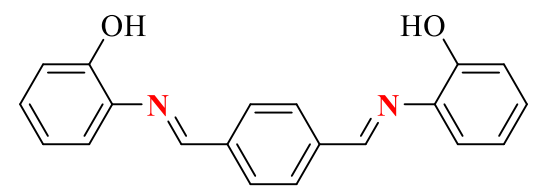

(39)

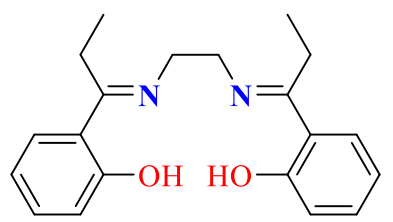

Schiff base

(41)<smiles>Nc1ccccc1/N=C/c1ccc(/C=N/c2ccccc2N)cc1</smiles>

(40)<smiles>CCC1=C2CCC3=C(CC)c4ccccc4O[C@@]3(N1)Oc1ccccc12</smiles>

Cu-complex

(42)

Fig. 1: Structures of targeted Schiff base and metal complexes. 
In a similar work, Ambika et al. (2019) studied the anti-cancer and anti-angiogenic properties of Schiff base metal complexes. They synthesized two Co(III) Schiff base complexes, trans-[Co(salen) $\left.\left.(\mathrm{DA})_{2}\right] 9 \mathrm{ClO}_{4}\right)$ and trans$\left[\mathrm{Co}(\right.$ salophen $\left.)(\mathrm{DA})_{2}\right]\left(\mathrm{ClO}_{4}\right)$ and characterized using various spectroscopic and analytical techniques. The cytotoxic activity of the newly synthesized compounds was conducted in vitro in A549 (human small cell lung carcinoma) and VERO (African green monkey kidney cells) adopting the MTT assay. While assessed separately, neither the metal ion nor the free ligand showed any activity up to $200 \mu \mathrm{m}$ concentrations while the former and the latter complex exhibited the $\mathrm{IC}_{50}$ values of $80 \mu \mathrm{m}$ and $65 \mu \mathrm{m}$ respectively showing the better activity of the second complex. The study revealed the potential use of such metal complexes in cancer chemotherapy and as an inhibitor of angiogenesis [56]. Benzimidazole belongs to such a potent scaffold that possesses a wide variety of functionalizations and coordination modes. In a study, a Schiff base (29) containing a benzimidazole moiety was synthesized from 2aminobenzimidazole and o-vanillin in the presence of a few drops of acetic acid. Its three copper complexes $(\mathbf{3 0}, \mathbf{3 1}$, and 32) were synthesized, one with the pure ligand, and the other with $\mathrm{N}, \mathrm{N}$-donor heterocyclic bases such as 1,10-phenanthroline and 2,2'-bipyridyl as co-ligands. They were tested for anticancer and NSAIDS studies. The in vitro cytotoxicity was conducted against MCF-7 cancer cell lines of human breast, of which compound (32) exhibited much better potency. This cytotoxic activity was attributed to ROS generation, as revealed by the lipid peroxidation and glutathione depletion studies. In further studies, compounds (30) and (32) showed significant anti-inflammatory and analgesic activities while assessed in vivo in albino rats and mice, at a lower concentration. The in silico studies revealed the interaction of the compounds with COX2 inhibitors; therefore the researchers forwarded the complexes (30) and (32) as promising NSAIDs candidates [57].
Three tridented Schiff base ligands $(\mathbf{3 3}, \mathbf{3 4}$, and 35) derived from pyrrole-2-carboxaldehyde and three amino acids, viz. L-methionine, L-histidine, and Ltryptophan were synthesized and complexed with palladium metal. The synthesis was carried out under inert conditions using Schlenk techniques. The compounds were characterized by elemental analysis, ${ }^{1} \mathrm{H}$ NMR, FTIR, UV-Vis, and conductivity measurements and found to be nonelectrolytic with square-planar geometry. The compounds were also tested for their antibacterial activity via the agar well diffusion method and the study was expanded to find out the MIC values employing the micro titer plate serial dilution method. While the compounds were assessed against four gram-positive and two gram-negative bacteria, the ligands did not exhibit any antibacterial action, but the complexes (38) were much bactericidal followed by (37 and 36). This selective effectiveness is due to the indole and imidazole tails of the respective compounds [58]. Saranya et al. (2020) studied the antimicrobial potency of metal complexes of tetradentate (39 and 40) Schiff bases synthesized by the condensation of 2-aminophenol/o-phenylenediaminewithtrerpthaldehyde, and $\mathrm{Cu}(\mathrm{II}), \mathrm{Co}(\mathrm{II})$, and $\mathrm{Ni}$ (II) metal salts. Compounds were synthesized by the general refluxation method and products were obtained from good to high yields (65-95\%). Antimicrobial tests were conducted against five bacterial pathogens and four fungal species. They found that the complexes were more active, if not completely resistant than the standards: antibiotic- ampicillin and fungicidemiconazole. It is noteworthy that the antibacterial activity of the metal complexes with Schiff base (40) is better [59].

Bao et al. (2020) synthesized a new Schiff base (41) from ethanediamine and 2hydroxyphenylacetone and its $\mathrm{Cu}(\mathrm{II})$ complex (42). They were characterized and evaluated for cytotoxicity of the same against different cell lines to explore them as cancer cell growth inhibitors. The complex was found to strongly suppress the growth of eight different types of malignant cells 
by different mechanisms [60]. The compound was found to have IC50 value in the range of 5.13-11.68 $\mu \mathrm{M}$ and less toxicity than cis-platin in LO2 and HUVEC cells.

\section{Conclusion and future perspective}

The metal complexes of Schiff bases are deeply rooted in medicinal chemistry. They have gained increasing attention in recent years owing to their versatile applications in various fields such as medicine, catalysis, electronics, industrial and material science. In this review, a collection of patents on Schiff bases and their metal complexes during 2015-2020 has been compiled. The reviewed articles cover various antimicrobial and anticancer applications of patented Schiff bases and their metal complexes. Several antimicrobial and anticancer drugs are already in clinical use, but the development of antimicrobial resistance and tumor resistance necessitates the development of new potent antimicrobial and antitumor drugs. Because of this, there is increasing interest in the design of effective drugs containing Schiff base scaffold and metal complexes. Another major area for therapeutic applications of Schiff bases is their use against mycobacteria causing tuberculosis. This is a serious concern in pharmaceutics to come over from tuberculosis because of increasing resistance to already available antituberculosis drugs. Considering the tremendous structural diversity of Schiff bases, the available literature is insufficient to expose the boundless potential for therapeutic uses of Schiff bases and their metal complexes. So, the future perspective as potent therapeutic drugs of Schiff base metal complexes is the decisive commentary of this review article.

\section{References}

[1] F. Glaser, O.S. Wenger, Recent progress in the development of transition-metal based photoredox catalysts, Coord. Chem. Rev. 405 (2020) 213129. http://dx.doi.org/10.1016/j.ccr.2019.213129.

[2] Y. Yang, X. Wu, C. He, J. Huang, S. Yin, M. Zhou, L. Ma, W. Zhao, L. Qiu, C. Cheng, C. Zhao, Metalorganic framework/Ag-based hybrid nanoagents for rapid and synergistic bacterial eradication, ACS
Appl. Mater. Interfaces. 12 (2020) 13698-13708. http://dx.doi.org/10.1021/acsami.0c01666.

[3] S.M. Abdallah, G.G. Mohamed, M.A. Zayed, M.S. Abou El-Ela, Spectroscopic study of molecular structures of novel Schiff base derived from ophthaldehyde and 2-aminophenol and its coordination compounds together with their biological activity., Spectrochim. Acta. A. Mol. Biomol. Spectrosc. 73 (2009) 833-840. https://doi.org/10.1016/j.saa.2009.04.005.

[4] D.A. Dias, S. Urban, U. Roessner, A historical overview of natural products in drug discovery, Metabolites. 2 (2012) 303-336. https://doi.org/10.3390/metabo2020303

[5] J. Bérdy, Thoughts and facts about antibiotics: where we are now and where we are heading, J. Antibiot. 65 (2012) 385-395. https://doi.org/10.1038/ja.2012.27.

[6] J.W.-H. Li, J.C. Vederas, Drug discovery and natural products: end of an era or an endless frontier?, Science. 325 (2009) 161-165. https://doi.org/10.1126/science.1168243.

[7] W. Qin, S. Long, M. Panunzio, S. Biondi, Schiff bases: a short survey on an evergreen chemistry tool, Molecules. 18 (2013) 12264-12289. https://doi.org/10.3390/molecules181012264.

[8] A. Rani, M. Kumar, R. Khare, H.S. Tuli, Schiff bases as an antimicrobial agent: A review, J. Biol. Chem. Sci. 2 (2015) 62-91.

[9] A. Chakraborty, P. Kumar, K. Ghosh, P. Roy, Evaluation of a Schiff base copper complex compound as potent anticancer molecule with multiple targets of action, Eur. J. Pharmacol. 647 (2010) 1-12. https://doi.org/10.1016/j.ejphar.2010.08.003.

[10]D. Gibson, Platinum(IV) anticancer prodrugs hypotheses and facts, Dalt. Trans. 45(2016) 1298312991. https://doi.org/10.1039/C6DT01414C.

[11]I. Romero-Canelón, P.J. Sadler, Next-generation metal anticancer complexes: multitargeting via redox modulation, Inorg. Chem. 52(2013) 1227612291. https://doi.org/10.1021/ic400835n.

[12] K. Brodowska, E. Łodyga-Chruscinska, Schiff bases - interesting range of applications in various fields of science, CHEMIK. 68 (2014) 132-134.

[13] Y. Jia, J. Li, Molecular assembly of Schiff base interactions: construction and application, Chem. Rev. 115 (2014) 15971621.

https://doi.org/10.1021/cr400559g.

[14] C.M. da Silva, D.L. da Silva, L. V. Modolo, R.B Alves, M.A. de Resende, C.V.B. Martins, Â. de Fátima, Schiff bases: a short review of their antimicrobial activities, J. Adv. Res. 2 (2011) 1-8. https://doi.org/10.1016/j.jare.2010.05.004.

[15] I. Kostova, L. Saso, Advances in research of Schiff-base metal complexes as potent antioxidants, Curr. Med. Chem. 20 (2013) 
$4609-4632$.

http://www.ncbi.nlm.nih.gov/pubmed/23834186.

[16] P. Jayaseelan, S. Prasad, S. Vedanayaki, R. Rajavel, Synthesis, characterization, anti microbial, DNA binding and cleavage studies of Schiff base metal complexes, Arab. J. Chem. 9(2011) S668-S677. https://doi.org/10.1016/j.arabjc.2011.07.029.

[17] A. Kajal, S. Bala, S. Kamboj, N. Sharma, V. Saini, Schiff bases: a versatile pharmacophore, J. Catal. 2013 (2013) $1-14$.

https://doi.org/10.1155/2013/893512.

[18] I. Kostova, L. Saso, Advances in research of Schiffbase metal complexes as potent antioxidants., Curr. Med. Chem. $20 \quad$ (2013) 4609-4632. https://doi.org/10.2174/09298673113209990149.

[19] S.H. Sumrra, M. Ibrahim, S. Ambreen, M. Imran, M. Danish, F.S. Rehmani, Synthesis, spectral characterization, and biological evaluation of transition metal complexes of bidentate $\mathrm{N}, \mathrm{O}$ donor Schiff bases, Bioinorg. Chem. Appl. 2014 (2014) 110. https://doi.org/10.1155/2014/812924.

[20] G. Ceyhan, C. Celik, U. Serhan, D. Ibrahim, M. Elmastas, M. Tümer, Antioxidant, electrochemical, thermal, antimicrobial and alkane oxidation properties of tridentate Schiff base ligands and their metal complexes, Spectrochim. Acta - Part A Mol. Biomol. Spectrosc. 81 (2011) 184-198. https://doi.org/10.1016/j.saa.2011.05.106.

[21] A.A. Abou-Hussein, W. Linert, Synthesis, spectroscopic, coordination and biological activities of some organometallic complexes derived from thio-Schiff base ligands, Spectrochim. Acta. A. Mol. Biomol. Spectrosc. $117 \quad$ (2014) 763-771. https://doi.org/10.1016/j.saa.2013.06.078.

[22] P.G. Cozzi, Metal-salen Schiff base complexes in catalysis: practical aspects., Chem. Soc. Rev. 33 (2004) 410-421. https://doi.org/10.1039/B307853C

[23] M. Shebl, Synthesis, spectroscopic characterization and antimicrobial activity of binuclear metal complexes of a new asymmetrical Schiff base ligand: DNA binding affinity of copper(II) complexes, Spectrochim. Acta - Part A Mol. Biomol. Spectrosc. 117 (2014) 127-137. https://doi.org/10.1016/j.saa.2013.07.107.

[24] K.J. Barnham, A.I. Bush, Biological metals and metal-targeting compounds in major neurodegenerative diseases, Chem. Soc. Rev. 43 (2014)6727-6749. https://doi.org/10.1039/C4CS00138A.

[25] S. Majumder, G.S. Panda, S.K. Choudhuri, Synthesis, characterization and biological properties of a novel copper complex, Eur. J. Med. Chem. 38 (2003)893-898. https://doi.org/10.1016/j.ejmech.2003.08.002.

[26] N. Farrell, Biomedical uses and applications of inorganic chemistry. An overview, Coord. Chem.
Rev. 232 (2002) 1-4.

[27] M.J. Hannon, Metal-based anticancer drugs: From a past anchored in platinum chemistry to a postgenomic future of diverse chemistry and biology, Pure Appl. Chem. 79 (2007) 2243-2261. https://doi.org/10.1351/pac200779122243.

[28] J. Reedijk, Medicinal applications of metal complexes binding to biological macromolecules, Macromol. Symp. $270 \quad$ (2008) 193-201. https://doi.org/10.1002/masy.200851023.

[29] G. Murtaza, M.K. Rauf, A. Badshah, M. Ebihara, M. Said, M. Gielen, D. De Vos, E. Dilshad, B. Mirza, Synthesis, structural characterization and in vitro biological screening of some homoleptic copper(II) complexes with substituted guanidines, Eur. J. Med. Chem. 48 (2012) 26-35. https://doi.org/10.1016/j.ejmech.2011.11.029.

[30] K. Shoaib, W. Rehman, B. Mohammad, S. Ali, Synthesis, characterization and biological applications of transition metal complexes of [NO] donor Schiff bases, J. Proteomics Bioinform. 6 (2013)153-157. https://doi.org/10.4172/jpb.1000274.

[31]C. Leelavathy, Arulantony, synthesis, spectral characterization and biological activity of metal(II) complexes with 4-aminoantipyrine derivatives, Spectrochim. Acta. A. Mol. Biomol. Spectrosc. (2013). https://doi.org/10.1016/j.saa.2013.04.055

[32]N.K. Chaudhary, P. Mishra, Metal complexes of a novel Schiff base based on penicillin: characterization, molecular modeling, and antibacterial activity study, Bioinorg. Chem. Appl. 2017 (2017). https://doi.org/10.1155/2017/6927675.

[33] N.K. Chaudhary, P. Mishra, Bioactivity of some divalent M(II) complexes of penicillin based Schiff base ligand: Synthesis, spectroscopic characterization, and thermal study, J. Saudi Chem. Soc. 22 (2018) 601-613. https://doi.org/10.1016/j.jscs.2017.10.003.

[34] E.N. Md Yusof, T.B.S.A. Ravoof, E.R.T. Tiekink, A. Veerakumarasivam, K.A. Crouse, M.I.M. Tahir, H. Ahmad, Synthesis, characterization and biological evaluation of transition metal complexes derived from $\mathrm{N}$, S bidentate ligands, Int. J. Mol. Sci. 16 (2015) 11034 11054. https://doi.org/10.3390/ijms160511034.

[35] S.A. Matar, W.H. Talib, M.S. Mustafa, M.S. Mubarak, M.A. AlDamen, Synthesis, characterization, and antimicrobial activity of Schiff bases derived from benzaldehydes and 3,3'diaminodipropylamine, Arab. J. Chem. 8 (2015) $850-857$.

https://doi.org/10.1016/j.arabjc.2012.12.039.

[36] G. Sridhar, M. Bilal.I, D. Easwaramoorthy, K. Rani.S, S. Kumar.B, C.S. Manohar, Synthesis, Characterization and Antimicrobial Activities of 
Copper, Nickel, Cobalt, Chromium Complexes Derived from (Z)-4-Fluoro-N-(2,7-dimethylhept-6enylidene) benzenamine, J. Brazillian Chem. Soc. 28 (2017) 756-767.

https://doi.org/10.21577/0103-5053.20160224.

[37] S. A. Moustafa, M.M. Ali, A. A. El-rashedy, Synthesis, anticancer activity and molecular docking study of Schiff base complexes containing thiazole moiety, Beni-Suef Univ. J. Basic Appl. Sci. 5(2016)85-96.

https://doi.org/10.1016/j.bjbas.2016.01.001.

[38] C.W. Dikio, B.J. Okoli, F.M. Mtunzi, Synthesis of new anti-bacterial agents : Hydrazide Schiff bases of vanadium acetylacetonate complexes, Cogent Chem. 4 (2017) 1-14. https://doi.org/10.1080/23312009.2017.1336864.

[39] H.F.G. Barbosa, M. Attjioui, A. Paula, G. Ferreira, E. Ralph, D. Id, N. Eddine, E. Gueddari, B.M. Moerschbacher, Synthesis, Characterization and Biological Activities of Biopolymeric Schiff Bases Prepared with Chitosan and Salicylaldehydes and Their Pd(II) and Pt(II) Complexes, Molecules. 22 (2017).

https://doi.org/10.3390/molecules22111987.

[40] H.F. Abd El-Halim, G.G. Mohamed, M.N. Anwar, Antimicrobial and anticancer activities of Schiff base ligand and its transition metal mixed ligand complexes with heterocyclic base, Appl. Organomet. Chem. (2017) 1-12. https://doi.org/10.1002/aoc.3899.

[41] J. Xie, S. Shen, R. Chen, J.U.N. Xu, K.U.N. Dong, J. Huang, Q.I.N. Lu, W. Zhu, T. Ma, L.E.I. Jia, H. Cai, T. Zhu, Synthesis, characterization and antitumor activity of Ln(III) complexes with hydrazone Schiff base derived from 2-acetylpyridine and isonicotinohydrazone, Oncol. Lett. 13 (2017) 44134419. https://doi.org/10.3892/ol.2017.6018.

[42] Y. Xiao, Q. Diao, Y. Liang, K. Zeng, Two novel Co (II) complexes with two different Schiff bases: inhibiting growth of human skin cancer cells, Brazilian J. Med. Biol. Res. 50 (2017) 2-6. https://doi.org/10.1590/1414-431X20176390.

[43] S. Kashyap, S. Kumar, K. Ramasamy, S.M. Lim, S.A.A. Shah, H. Om, B. Narasimhan, Synthesis, biological evaluation and corrosion inhibition studies of transition metal complexes of Schiff base, Chem. Cent. J. 12 (2018) 1-10. https://doi.org/10.1186/s13065-018-0487-1.

[44] S. Shaygan, H. Pasdar, N. Foroughifar, M. Davallo, F. Motiee, Cobalt (II) complexes with Schiffbase ligands derived from terephthalaldehyde and orthosubstituted anilines: Synthesis, characterization and antibacterial activity, Appl. Sci. 8 (2018). https://doi.org/10.3390/app8030385.

[45] H.A. El-Boraey, O.A. EL-Gammal, Novel (N4)
Macrocyclic Metal Complexes: Synthesis, Characterization, Spectral Studies and Anticancer Activity, Open Chem. J. 5 (2018) 51-63. https://doi.org/10.2174/1874842201805010051.

[46] K. Hu, C. Liu, J. Li, F. Liang, Copper(II) complexes based on quinoline-derived Schiff-base ligands: synthesis, characterization, HSA/DNA binding ability, and anticancer activity, Medchemcomm. 9 (2018) 1663-1672. https://doi.org/10.1039/C8MD00223A.

[47] K. Andiappan, A. Sanmugam, E. Deivanayagam, K. Karuppasamy, H.S. Kim, D. Vikraman, In vitro cytotoxicity activity of novel Schiff base ligandlanthanide complexes, Sci. Rep. 8 (2018) 1-12. https://doi.org/10.1038/s41598-018-21366-1.

[48] F. Chioma, A.C. Ekennia, A.A. Osowole, S.N. Okafor, C.U. Ibeji, D.C. Onwudiwe, O.T. Ujam, Synthesis, characterization, in-vitroantimicrobial properties, molecular docking and DFT studies of 3-\{(E)-[(4,6-dimethylpyrimidin-2-yl)imino]methyl $\}$ naphthalen-2-ol and Heteroleptic Mn(II), Co(II), $\mathrm{Ni}(\mathrm{II})$ and $\mathrm{Zn}$ (II) complexes, Open Chem. 16 (2018) 184-200. https://doi.org/10.1515/chem-2018-0020.

[49] M. Kuate, M.A. Conde, K.N. Nchimi, A.G. Paboudam, S.-J.E. Ntum, P.T. Ndifon, Synthesis, characterization and antimicrobial studies of $\mathrm{Co}(\mathrm{II})$, $\mathrm{Ni}(\mathrm{II}), \mathrm{Cu}(\mathrm{II})$ and $\mathrm{Zn}$ (II) complexes of (E)-2-(4dimethylbenzydimino)-Glycylglycine, (GlyglyDAB) a Schiff Base Derived from 4Dimethylaminobenzaldehyde and glycylglycine, Int. J. Org. Chem. 08 (2018) 298-308. https://doi.org/10.4236/ijoc.2018.83022.

[50] R.J. Melander, D. V. Zurawski, C. Melander, Narrow-spectrum antibacterial agents, Medchemcomm. 9 (2018) 12-21. https://doi.org/10.1039/C7MD00528H.

[51] A.S. Abu-khadra, A.S. Afify, A. Mohamed, R.S. Farag, Y. Hassan, Preparation, characterization and antimicrobial activity of Schiff base of (E)-N-(4-(Thiophen2ylmethyleneamino) Phenylsulfonyl) Acetamide metal complexes, Open Bioact. Compd. J. 6 (2018) 1-10. https://doi.org/10.2174/1874847301806010001.

[52] C. Festus, S.N. Okafor, A.C. Ekennia, Heteroleptic metal complexes of a Pyrimidinyl based Schiff base ligand incorporating 2,2'-Bipyridine moiety: synthesis, characterization, and biological studies, Front. Chem. 7 (2019) 1-12. https://doi.org/10.3389/fchem.2019.00862.

[53] B.H. Al-zaidi, M.M. Hasson, A.H. Ismail, New complexes of chelating Schiff base: Synthesis, spectral investigation, antimicrobial, and thermal behavior studies, J. Appl. Pharm. Sci. 9 (2019) 4557. https://doi.org/10.7324/JAPS.2019.90406.

[54] S.A. Al-aghbari, O.M. Al-shuja, R. Al-badani, A.A.M. Japir, Synthesis, characterization and anticancer activity studies of new Schiff base Pt (II) 
complex, J. Mater. Sci. Chem. Eng. 7 (2019) 1-8. https://doi.org/10.4236/msce.2019.78001.

[55] J. Denga, P. Yu, Z. Zhang, J. Zhang, Z. Sun, M. Cai, H. Yuan, H. Liang, F. Yang, Novel Pt(II) complexes with modified aroyl-hydrazone Schiff- base ligands: synthesis, cytotoxicity and action mechanism, Metallomics. (2019). https://doi.org/10.1039/C9MT00193J.

[56] S. Ambika, Y. Manojkumar, S. Arunachalam, B. Gowdhami, K.K.M. Sundaram, R.V. Solomon, P. Venuvanalingam, M.A. Akbarsha, M. Sundararaman, Biomolecular interaction, anticancer and anti-angiogenic properties of Cobalt (III) Schiff base complexes, Sci. Rep. 9 (2019) 114. https://doi.org/10.1038/s41598-019-39179-1.

[57] A. Hussain, M.F. Alajmi, T. Rehman, S. Amir, F.M. Husain, A. Alsalme, M.A. Siddiqui, A.A. AlKhedhairy, R.A. Khan, Copper (II) complexes as potential anticancer and Nonsteroidal anti- inflammatory agents: In vitro and in vivo studies, Sci. Rep. 9 (2019) $1-17$.

https://doi.org/10.1038/s41598-019-41063-X.

[58] E.A. Nyawade, M.O. Onani, S. Meyer, P. Dube, Synthesis, characterization and antibacterial activity studies of new 2-pyrral-L-amino acid Schiff base palladium (II) complexes, Chem. Pap. (2020). https://doi.org/10.1007/s11696-019-00986-5.

[59] J. Saranya, S. Jone Kirubavathy, S. Chitra, A. Zarrouk, K. Kalpana, K. Lavanya, B. Ravikiran, Tetradentate Schiff base complexes of transition metals for antimicrobial activity, Arab. J. Sci. Eng. 45 (2020) 4683-4695. https://doi.org/10.1007/s13369-020-04416-7.

[60] R.-D. Bao, X.-Q. Song, Y. Kong, F. Li, W.-H. Liao, J. Zhou, J. Zhang, Q.-H. Zhao, J.-Y. XU, C. Chen, M.-J. Xie, A new Schiff base copper(II) complex induces cancer cell growth inhibition and apoptosis by multiple mechanisms, J. Inorg. Biochem. (2020). https://doi.org/10.1016/j.jinorgbio.2020.111103. 